OPEN ACCESS

Edited by: Geneviève Pagé, University of Quebec in Outaouais,

Canada

Reviewed by:

Fabricio Chicca,

Victoria University of Wellington,

New Zealand

Irtifa Mukhter,

University of Delhi, India

*Correspondence:

Gwen D. Erlam

gerlam@aut.ac.nz

Specialty section:

This article was submitted to Educational Psychology,

a section of the journal

Frontiers in Education

Received: 10 December 2020 Accepted: 20 September 2021

Published: 12 October 2021

Citation:

Erlam GD, Garrett N, Gasteiger N,

Lau K, Hoare K, Agarwal S and Haxell A (2021) What Really Matters:

Experiences of Emergency Remote

Teaching in University Teaching and Learning During the COVID-

19 Pandemic.

Front. Educ. 6:639842.

doi: 10.3389/feduc.2021.639842

\section{What Really Matters: Experiences of Emergency Remote Teaching in University Teaching and Learning During the COVID-19 Pandemic}

\author{
Gwen D. Erlam ${ }^{1 \star}$, Nick Garrett ${ }^{2}$, Norina Gasteiger ${ }^{3}$, Kelvin Lau ${ }^{1}$, Kath Hoare ${ }^{1}$, \\ Shivani Agarwal ${ }^{1}$ and Ailsa Haxell ${ }^{1}$
}

${ }^{1}$ School of Public Health and Interdisciplinary Studies, Auckland University of Technology, Auckland, New Zealand, ${ }^{2}$ Department of Biostatistics and Epidemiology, Auckland University of Technology, Auckland, New Zealand, ${ }^{3}$ School of Health Sciences, University of Manchester, Manchester, United Kingdom

The COVID-19 pandemic and related lock downs have accelerated the need for online and remote teaching within university settings. However, due to the abrupt nature of the pandemic, many academic staff were not prepared for this forced transition. This study aimed to understand how the pandemic affected academics at a New Zealand university, with regards to their transition to emergency remote teaching. Specifically, it explores the challenges as well as benefits academics experienced during this transition. Recommendations for future online learning are also made. Academic staff $(N=67)$ at a New Zealand University completed an anonymous online survey. Quantitative data were analyzed statistically using descriptive and inferential statistics, while qualitative data were analyzed thematically. Major challenges experienced included miscommunication from the university, concerns about student access to technology, finding a quiet space to work, lack of digital competence skills, too much screen-time, managing work hours, and work/ life balance. Benefits included enhanced flexibility, enhanced teacher creativity, increasing autonomy of learners, and reduced commute time. Looking forward, academic staff desired future teaching to include blended learning and virtual immersion. New strategies of working remotely are being explored to facilitate teaching and learning while catering to the preferences and skills of both educators and students. Our findings honor the considerable agility of academic staff who sought to sustain and enhance excellence in remote education. At an institutional level our findings point to the need for staff to be supported by their institutions as they further refine their work within new-found spaces.

Keywords: COVID-19, higher education, teaching and learning, blended learning (BL), pandemic, learning organizations, emergency remote education

\section{INTRODUCTION}

\subsection{Online and Remote Learning}

The history of teaching and learning in higher education settings has predominantly been face-toface. However, other modes involving distance learning have developed in parallel, including education by postal correspondence and radio and television courses (e.g. United Kingdom's Open University). More recently, lives and education have further shifted as our world has 
become more digital (Bearman et al., 2020). For many, turning to Google or YouTube to search for information or learn a skill is common practice (Bhatt and MacKenzie, 2019). Unsurprisingly, formal learning is also increasingly positioned online. Selwyn (Selwyn, 2016, p. 6) notes, "The confluence of technology and education is complicated, contradictory and messy." This is reflected in current times, whereby the pandemic has accelerated, and for some forced, the transition to fully remote teaching and learning. Online and remote forms of education have occurred in Australia and New Zealand since around 1922 (White, 1982; Bewley, 1996; Seelig et al., 2019). In the University where this study takes place, online and remote teaching prior to 2020 was a generally limited to specific undergraduate courses, however very few were offered fully online.

\subsection{Pivoting to Emergency Remote Teaching and Learning During the COVID-19 Pandemic}

The COVID-19 pandemic hastened applications of digital teaching and learning (Houlden and Veletsianos, 2020). As a result, many educators did not have the necessary digital literacy skills. Furthermore, a clear vision for what was required may have been lacking (Dhawan, 2020). A digital pedagogical pivot (Anderson, 2020) as an emergency remote teaching option needed to occur quickly and efficiently.

In New Zealand, the government imposed a level four national lockdown to limit and control community transmission of COVID-19 on March 26, 2020 (New Zealand Government, 2020). The entire population was required to stay at home and shelter "in their bubble" (except for essential workers or those experiencing an emergency). Travel was severely restricted with all gatherings cancelled and public venues closed (New Zealand Ministry of Health, 2020). While some remote learning has been occurring over many years (Ralston, 2020), the pandemic accelerated this process and expanded its scope causing what has been identified in the international literature as "emergency remote teaching" (Hodges et al., 2020). The terms "emergency remote teaching" and "online teaching and learning" have both been used in the context of the pandemic event and need to be appropriately defined for the purposes of this research.

Emergency remote teaching (ERT) is a temporary shift of instructional delivery to an alternate mode due to crisis circumstances (Hodges et al., 2020). It involves the use of fully remote teaching solutions for instruction and education that would otherwise be delivered face-to-face or as blended courses. While this research focused on ERT, the term "online teaching and learning" was used extensively throughout the survey. This is because the term ERT is not commonly used in New Zealand and so would be unfamiliar to participants. In contrast, online learning is both a social and a cognitive process (Conole, 2021), not merely a matter of information transmission via remote information technologies. Careful planning for online learning therefore includes not only identifying the content to cover but also consideration of how different types of interactions will be supported and prioritized. Consequently, development of online courses may take up to 9 months.
Key components of successful online and remote educators are identified as including passion for the work, confidence to move forward, and the skills to successfully make the transition (Wieland and Kollias, 2020). All three of these key influences are likely to have been negatively impacted by the pandemic. Passion may have been muted by the abruptness of a forced transition while concurrently navigating stressors associated within family life (e.g. working from home whilst also homeschooling). Confidence with teaching is likely to be diminished, when the medium requires digital expertise in new technologies and communication skills (König et al., 2020; Marshall et al., 2020; Pather et al., 2020).

Additionally, deep-rooted issues experienced by academic staff were accentuated during the pandemic, including concerns of equity, disinvestment, and shifting teaching and learning platforms (Sălceanu, 2020). At an organizational level challenges included the lack of consideration for sustainability relating to abrupt closure of all campuses, a lack of practiced communication pathways for disseminating information rapidly, and staff inexperienced in finding resources and personnel while working remotely.

\subsection{Teaching and Learning Remotely in an Emergency}

There is evidence that ERT has equivalence with on-campus environments with respect to key outcomes such as student success (McPhee and Söderström, 2012) and student satisfaction measures (Palmer, 2012). There is also evidence that ERT benefits educators (Roddy et al., 2017) with expansion of networks providing a related increase in opportunities to work collegially. The impact of COVID-19 and the subsequent effect on the operations of the university raises questions around institutional priorities and strategies to achieve these positive teaching and learning experiences in constrained circumstances.

Remote teaching occurred prior to the pandemic with most academics having some level of familiarity with email, accessing information through digital library systems, and some knowledge of learning management systems. However, working exclusively at a distance from students, colleagues, and institutional support systems may have generated additional challenges. The University where this research was conducted provided some support to ensure smooth running of digital platforms which was accessible by academics. There were also links on the university website to the Ministry of Education which may have been of assistance. However, the extent to which these resources were utilized remains unclear.

While learning is frequently posited as something students do, learning how to teach remotely became a major focus for academic staff. This global phenomenon impacted educators worldwide. However, it also provided collaboration which might not have otherwise occurred. For example, the European Institute for Innovation and Technology provided accessible resources for online teaching in higher education (EIT InnoEnergy, 2020). E-collaborations became frequent (Favale et al., 2020). This was important as most higher 
education institutions were forced to pursue some form of remote education during the pandemic (Houlden and Veletsianos, 2020). Some universities became part of an international and collegial network with the aim of keeping institutions both economically and educationally viable (Nicola et al., 2020).

Tertiary institutions and researchers are now increasingly learning from the experience of academics, as subsequent waves of COVID-19 are resulting in repeated lockdowns and closures. As of November 2020, 32.7\% of total enrolled learners are studying remotely, which accounts for 30 country-wide closures (UNESCO Institute for Statistics data, 2020). Specifically, universities are exploring educator experiences to determine what can be done to improve current teaching (Whittle et al., 2020; König et al., 2020). This additional digital expertise, on top of what was already being required, has contributed to exhaustion and in some cases burn-out of academic staff (Eagle Hill Consulting, 2020; Pather et al., 2020). For many, the creativity and energy required to transition to remote teaching was overwhelmed by the need to "survive" and secure essential food and supplies for the pandemic lockdown (Almost, 2020).

Recently published research from Germany, Australasia, India and the United States has explored educator experiences of emergency remote teaching during the COVID-19 pandemic (Cameron-Standerford et al., 2020; Gamage et al., 2020; Irtifa and Richa, 2020; König et al., 2020; Marshall et al., 2020; Pather et al., 2020). However, to date, there is limited research on the experiences of academics during the pandemic, including support mechanisms and unintended benefits. Additionally, as identified by Sokal et al. (2020), there remains a need for research that explores the influence of internal and external factors on stress experienced by academic staff during the COVID-19 pandemic. While there is considerable interest in the experience of remote teaching globally, knowing how this was experienced locally (i.e. within New Zealand), along with strategies in how to better manage working with students and colleagues requires further exploration.

The aim of this study is to understand how the COVID-19 pandemic (with its subsequent lockdowns and isolation bubbles) affected academics in a health faculty at a university in Auckland, New Zealand with regards to their transition to platforms for emergency remote teaching. Specifically, it explores the personal, social, institutional and student-related challenges experienced during the transition as well as identifying the emerging benefits during the accelerated transition. Recommendations for future online and remote teaching and learning were also made by asking academics to pause and reflect on the effects to their personal and professional lives. Consideration is given to strategies perceived as effective, to better prepare for the future-a movement into a new Frontier.

\section{MATERIALS AND METHODS}

\subsection{Setting and Sample}

This cross-sectional survey study was approved by the university Ethics Committee (Reference 20/266) and was conducted during the COVID-19 pandemic from September to October 2020.
During this time New Zealand had eased out of a national lockdown, but uncertainty remained as regions moved up and down different alert levels. For example, Auckland moved into a regional lockdown due to uncontrolled community transmission from 12 August until the 30th August 2020. This meant that teaching continued remotely in an emergency mode. Academic institutions in Auckland reopened for the second time on October 7, 2020. The survey covered reflections on the initial experience of ERT during the first lockdown in March, as well as during the second lockdown when the survey was distributed, and into the future.

Participants were recruited from a New Zealand university. This included respondents from four schools within a Science and Health Faculty. A total of 497 academic staff employed across the Faculty and were invited to participate in the study.

Faculty participating in this research encompassed the following subject areas: Clinical health sciences, psychological studies, exercise science, nutrition, environmental health, medical laboratory science, food science, and public health. The courses in clinical health science, exercise science, food science, psychology, and environmental health involve primarily practical components including clinical and "industry" placements. The courses in medical laboratory science, nutrition, and public health involve primarily theoretical and laboratory components.

Before the pandemic the primary pedagogical approach was face-to-face teaching and courses were often taught in a classroom-based setting with associated labs and tutorials. Students then proceeded to relevant clinical placements as required by professional qualifications. There was some expertise in online pedagogical approaches with some remote teaching in large undergraduate courses, but this expertise was not widespread. When the lockdown occurred, many face-toface laboratories and clinical placements ceased while virtual labs and simulations were added or expanded in some courses. There was also need for additional student engagement and support through group and one-on-one sessions via virtual office hours.

\subsection{Procedures and Measures}

\subsubsection{Recruitment}

The inclusion criteria were academic staff working in the Faculty during the COVID-19 lockdowns. Staff had to be living in New Zealand and involved in teaching and learning during the level four lockdown. Due to the potential limitation on recruitment caused by the survey being distributed while many staff were still working remotely, no upper limit for respondents was set.

Participants were recruited through the Faulty Teaching and Learning Network, campus posters with QR codes linking to a research survey, and word of mouth. Data collection occurred between lockdowns when access to the campus was modestly restored. The survey link provided both participant information and access to the online survey, which was hosted on Qualtrics.

Consent was obtained from respondents by requiring a circle be ticked at the beginning of the survey. No identifying information was collected, to preserve anonymity. 
Additionally, the raw data on Qualtrics was password-protected with only the research team having access.

\subsubsection{Survey Development}

The survey was developed after reviewing other surveys with similar aims in Australia, New Zealand (Flack et al., 2020; Pather et al., 2020), and around the world (Aristovnik et al., 2020; Cameron-Standerford et al., 2020; Kawaguchi-Suzuki et al., 2020; Mahdy, 2020; Rapanta et al., 2020). Initially, a framework of key domains of interest within the research focus were developed. Existing survey questions were then identified to fit within the domains. Where there were gaps, existing questions were adapted, or new questions were developed. The survey instrument was peer-reviewed by an external researcher with expertise in educational research, and trialed by several staff within the Faculty, before the survey was implemented. The central focus of this research was, "What factors influenced your remote teaching and learning practice during the COVID-19 lockdowns?" The questions were modified to match the aims of this research.

Overall categories of impact were developed in order to give a clearer structure and intent to the survey. The categories included six sections. In the first five sections, respondents were asked to rate items in order of importance and respond to Likert-scale questions. Section one addressed demographics (e.g. age, ethnicity, school affiliated with, years of tertiary teaching experience. Section two addressed communication issues as the lockdown unfolded (e.g. most challenging and most beneficial communications from university during lockdown). Section three addressed resources related to Information Technology (IT) available to educators as well as the speed and type of Internet access. Section four addressed issues emerging when working from home and online (e.g. available quiet space, access to technology, digital competence). Section five focused on academic experiences while teaching remotely. Finally, section six focused on how the university might look in the future. This section contained five questions which allowed for open-text responses. The survey took between 10 and $15 \mathrm{~min}$ to complete.

\subsection{Data Analysis}

\subsubsection{Quantitative Analysis}

The quantitative analysis was primarily descriptive, producing frequencies, percentages and mean scores or ranks to present the survey data. SAS version 9.4 (www.sas.com) was used for data management and statistical analysis.

An analysis of all survey questions demonstrated no significant correlation for the order in which options for each question were presented and the preferences of respondents (Spearman's rank correlation $p=0.74$ ), which indicates that there is no significant bias introduced by the order in which options appear.

\subsubsection{Qualitative Analysis}

Qualitative analysis involved responses to the open-ended questions being analyzed thematically in accordance with the Braun and Clarke (2006) framework. An inductive process was
TABLE 1 | Participant demographics $(n=67)$.

\begin{tabular}{|c|c|c|}
\hline & No & $\%$ \\
\hline \multicolumn{3}{|l|}{ Age (years) } \\
\hline $20-30$ & 4 & 6.3 \\
\hline $31-40$ & 13 & 20.3 \\
\hline $41-50$ & 23 & 35.9 \\
\hline $51-60$ & 13 & 20.3 \\
\hline Over 60 & 11 & 17.2 \\
\hline Not specified & 3 & - \\
\hline \multicolumn{3}{|l|}{ Ethnicity } \\
\hline Māori & 3 & 4.5 \\
\hline Pacific & 2 & 3.0 \\
\hline Asian & 8 & 11.9 \\
\hline Pakeha/New Zealand European & 34 & 50.8 \\
\hline Other European & 14 & 20.9 \\
\hline Other & 8 & 11.9 \\
\hline \multicolumn{3}{|l|}{ School } \\
\hline Public Health and Interdisciplinary Studies & 34 & 50.8 \\
\hline Clinical Sciences & 24 & 35.8 \\
\hline Sport and Recreation & 1 & 1.5 \\
\hline Science & 8 & 11.9 \\
\hline \multicolumn{3}{|l|}{ Tertiary teaching experience (years) } \\
\hline$<2$ & 7 & 10.6 \\
\hline $2-5$ & 10 & 15.2 \\
\hline $6-10$ & 13 & 19.7 \\
\hline $11-20$ & 21 & 31.8 \\
\hline $20 \leq$ & 15 & 22.7 \\
\hline Not reported & 1 & - \\
\hline \multicolumn{3}{|l|}{ Experience with online teaching } \\
\hline Extensive experience & 15 & 23.4 \\
\hline Some previous experience & 32 & 50.0 \\
\hline This is my first experience & 17 & 26.6 \\
\hline
\end{tabular}

utilized, whereby the content of the data directed the coding and theme development process. Two researchers initially familiarized themselves with the data by reading through it. They then independently coded the data by assigning codes and provisional themes to establish further credibility in the analysis and representation of the data (Thomas and Harden, 2008). A second reading focused on the development of preliminary codes and identification of patterns within the responses (initial themes). Saturation was evident when no additional data were found to further develop the properties of each theme. These were then considered by further two other members of the research team, resulting in further refinement of the themes, ensuring that the themes identified were relevant to the research question and added depth to the quantitative results. Discussions then occurred with all members of the team in gaining further consensus, contributing to the credibility and trustworthiness of the analysis. The qualitative data are reported alongside the quantitative data, adding richness and depth relating to the respondents' experiences of ERT.

\subsubsection{Triangulation of Results}

Multiple sources of data were included in this research in order to align several perspectives and lead to a more comprehensive understanding of the research question. In this research triangulation involved combining results from three data sources (i.e. the literature review, quantitative survey data and 
TABLE 2 | Communication issues experienced during the initial lockdown.

\begin{tabular}{|c|c|c|c|c|c|c|}
\hline Communication issues in order of importance $(n=65)$ & Average rank & 1st (\%) & 2nd (\%) & 3rd (\%) & 4th (\%) & 5th (\%) \\
\hline Speed with which lock down occurred & 2.9 & 23.1 & 29.2 & 35.4 & 1.5 & 10.8 \\
\hline Lack of communication or conflicting messages from organization & 2.6 & 13.8 & 21.5 & 36.9 & 13.8 & 13.8 \\
\hline Immediate switch to block format, then out of block format & 2.1 & 29.2 & 20.0 & 13.8 & 15.4 & 21.5 \\
\hline Media coverage emerging around AUT & 3.9 & 20.0 & 20.0 & 7.7 & 35.4 & 16.9 \\
\hline Mastering new technologies (e.g. Teams, Zoom, Bb Collaborate) & 3.6 & 13.8 & 9.2 & 6.2 & 33.8 & 36.9 \\
\hline
\end{tabular}

qualitative open responses). A convergence of information from these three sources was used to explore various aspects of the research question.

\section{RESULTS}

\subsection{Participant Summary}

A total of 76 individuals were recruited and started the online survey. Of these 76 respondents, six did not answer any questions, one did not give consent, and two only completed demographic information. Therefore, data was included for 67 respondents for analysis (13.5\% of target population). The median amount of time required for survey completion was $12 \mathrm{~min}$.

Table 1 summarizes the key characteristics of the sample. Approximately $40 \%$ were aged 51 years or older. Half (50\%) identified as New Zealand European. All four of the faculty schools were represented, however, half of the respondents were staff in the School of Public Health and Interdisciplinary Studies and only one staff member from the School of Sport and Recreation participated.

Regarding teaching experience, $32 \%$ of the sample reported between 11 and 20 years of experience. Twenty-three percent of respondents reported more than 20 years of experience, and $20 \%$ reported between six and 10 years. The remaining $26 \%$ had less than 5 years of experience. Half (50\%) of the respondents had some previous experience with online teaching and $23 \%$ reported extensive experience. However, this experience may not have been current or involving the tools and materials that were available during lockdown. Therefore, because the contexts were so different, there were no comments about previous online teaching experiences in the survey responses. However, $27 \%$ reported the transition to ERT during the COVID-19 pandemic as being their first experience teaching remotely. The over-representation of educators who did not have experience working in digital platforms was concerning due to additional potential stress. Furthermore, learning in this space requires strategies which enhance student engagement (Pentaraki and Burkholder, 2017) which may not have been in the educator "toolkit."

\subsection{Challenges Experienced}

\subsubsection{Communication Challenges}

Participants were asked to rank several key communications issues (from 1 to 5 ) that eventuated during the lockdown period (Table 2). On average, the highest-ranking communication issue was the university-wide decision at the beginning of the level four lockdown to switch to a block format of delivery from the previous semester delivery (average rank 2.1). This decision was reversed 2 weeks later, after consultation with stakeholders. In the interim, academics were forced to reconfigure calendars, due dates, and overall delivery of their courses with a subsequent return to original timetables.

On average, the second highest ranked communication issue was the lack of communication (or conflicting messages) from the University (average rank 2.6). However, only $14 \%$ of respondents ranked this as the most important issue. The next most important communication issue reported was the speed with which the lockdown occurred (average rank 2.9). New Zealand was given approximately 2 days (March 23-25) to prepare for the lockdown. Although on average, this issue ranked lower than lack of communications, a higher proportion $(23 \%)$ ranked this as the most important. The next most important issue was mastering new technologies (average rank 3.6) with $14 \%$ of respondents identifying this as the most important communication issue.

On average, the lowest ranked of these communication issues was the fact that during the lockdown the university experienced significant challenges involving media coverage of senior staff along with negative stakeholder response to the block format (average ranking 3.9). However, 20\% of respondents ranked this issue as the most important.

The challenges relating to communications were expanded upon in the qualitative data, whereby communication from management was sometimes experienced as an additional and frustrating stressor. A concern for the relational work involved was repeatedly reported. This encompassed work with students and colleagues which was expected of the university as a learning institution.

\subsubsection{IT Resources and Support During Pivot to Emergency Remote Teaching}

Figure 1 presents summary data on how academics scored the challenges relating to IT support that have previously been identified as key for the transition to ERT. On average, the most challenging resource issue reported was students' access to technology/equipment (average score 2.21). This is emphasized when examining the challenge categories where it was somewhat or very challenging for $91 \%$ of academics.

The second highest average score was finding a quiet space to work from home (average score 1.97). When looking across all three responses for this issue, approximately one third is reflected for each category. This indicates that for approximately one third 


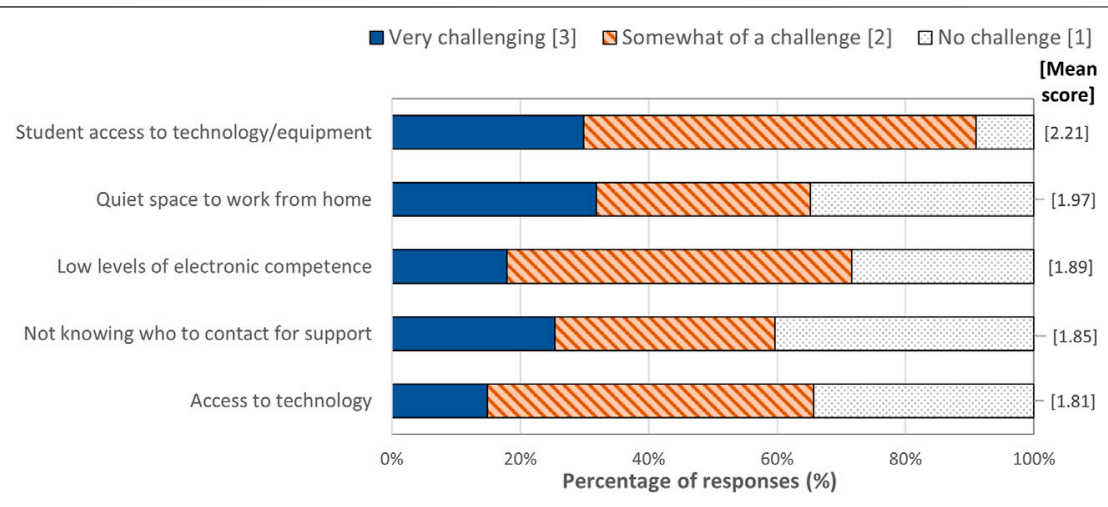

FIGURE 1 | Challenges in IT resources and support when transitioning to online teaching.

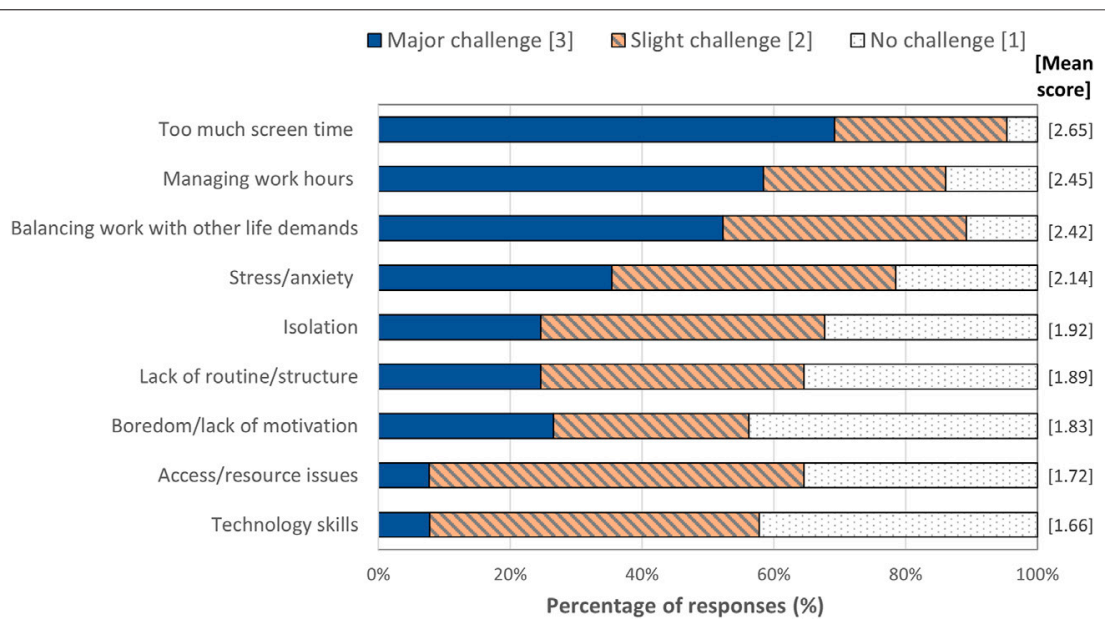

FIGURE 2 | Challenges experienced while working from home, during the initial lockdown.

of respondents this was not a challenge, but for two thirds of respondents it was somewhat or very challenging (65\%).

The third highest average score in the area was low levels of electronic competence (average score 1.89). However, a majority (82\%) found this only somewhat challenging or not challenging at all. This indicates that it was not an overwhelming issue for most respondents. Similar patterns were evident for not knowing who to contact for support (average score 1.85) and access to technology (average score 1.81).

These IT-related challenges were also reflected in the qualitative data. The abruptness of pivoting one's work into remote spaces relied heavily on expectations that academic staff and students would have the software, hardware and enough Internet connectivity to make this possible. While this was the case for most, respondents expressed concern for those who may be in a less privileged space. Such concern was framed as one of equity. Equity involved academic staff having both the tools required for ERT, and the skills involved to avoid student disadvantage. Some academic staff also struggled with how to make use of what was available.
3.2.3 Challenges Emerging When Working From Home Challenges of working from home given the speed of the initial lockdown are presented in Figure 2. The highest scored challenge reported was too much screen time (average score 2.65). This issue was reported as a slight or major challenge for $95 \%$ of respondents.

The next highest challenges were attributed to managing work hours (average score 2.45) and balancing work with other life demands (average score 2.42). There was either a slight or major challenge for 86 and $89 \%$ of respondents respectively. Interestingly, the fourth highest average issue was stress/ anxiety (average score 2.14) which was a slight or major challenge for $79 \%$ of respondents when working from home.

Isolation (average score 1.92), lack of routine/structure (average score 1.89) and boredom/lack of motivation (average score 1.83) all had similar patterns reported with $25-27 \%$ of respondents reporting that these were major challenges, with an additional $30-43 \%$ reporting some challenges.

The lowest rated challenges were access resource issues (average score 1.72) and technology skills (average score 


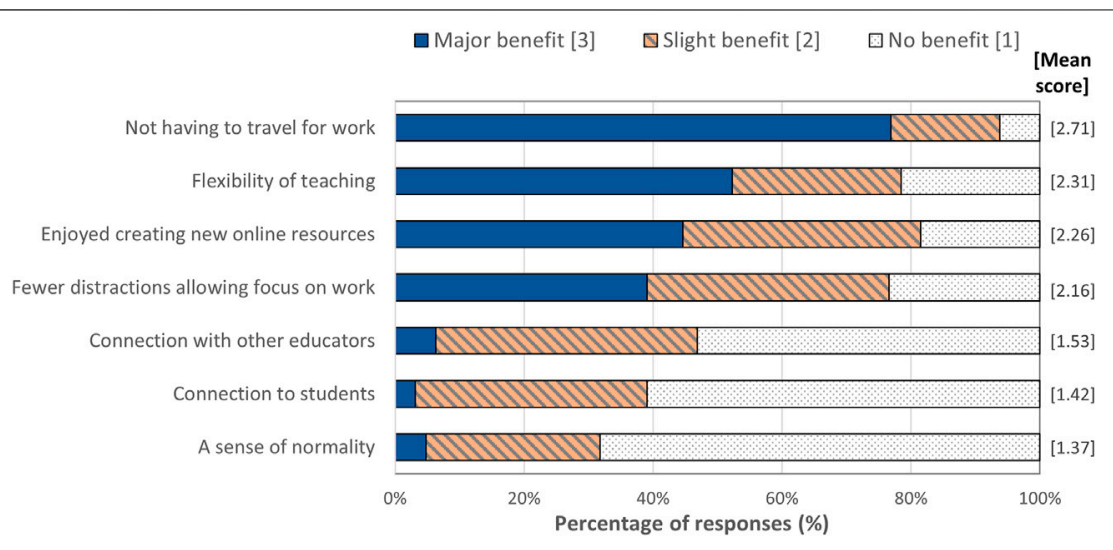

FIGURE 3 | Benefits of working from home during the initial lockdown.

1.66), however there was still a large proportion of the respondents who found challenges with these issues. While only $8 \%$ of respondents for both issues rated them as very challenging, there were 69 and $60 \%$ respectively who found there were some challenges present.

As reported in the qualitative data, the physicality of one's place of work remains an area of undeniable importance. Participants reported that the reconfiguration of space in which to work was challenged not only by the equipment availability (e.g. desks, chairs computers and monitors) but also by disparate factors. These included living in places poorly served by Internet providers, or where the Internet connectivity was insufficient for the demands of multiple people requiring access from home. Other academic staff reported an inability to find private spaces to engage in workrelated conversations or from which to provide lectures or tutorials. Academic staff also expressed an empathetic understanding that the challenges they needed to negotiate were likely shared by their students.

\subsection{Recognized Benefits of Working From Home}

While difficulties were reported with working from home, there were some benefits reported from this experience (Figure 3). Survey respondents on average reported that not traveling to work was the most significant benefit (average score 2.71). A high proportion of respondents $(94 \%)$ found this issue a slight or major benefit.

The next highest scored benefits reported were flexibility in teaching (average score 2.31), followed by an opportunity to create online resources (average score 2.26), with $45-52 \%$ reporting these new challenges eventuating from the lockdown as producing major benefits. The fourth highest scored benefit was having fewer distractions allowing for greater focus at home (average score 2.16). This is likely because a quiet home space may limit distractions by colleagues and other events occurring around buildings and on-campus areas.

The lowest rated benefits were connections with other educators (average score 1.53), connection with students (average score 1.42) and a sense of normality (average score 1.37). For these issues major benefits were only reported for 3-6\% of respondents, however of interest is that $30-40 \%$ reported that there were slight benefits.

Academic staff reported various unexpected benefits while working from home. Within the qualitative data, a surprising sense of togetherness was most evident. Despite geographical isolation, online media provided a platform for connecting with students and colleagues. Being able to utilize such spaces, both formally and informally, supported the collective purpose of staff trying to do their best by students. The novelty, as well as a pressured timeline, substantially increased the workload for most respondents. This took the form of reflecting on and developing new ways of working, needing to innovate, and creating or adapting learning and teaching resources. Strongly voiced in the open-ended responses was that this occurred within a strongly supportive and collegial environment. A sense of belonging within a community of similarly challenged others is evident with responses demonstrating empathy, trust and a non-judgmental space for staff to ask, share and practice with each other.

Academics were also asked about the positive aspects of online/ distance education (Figure 4). The highest average reported positive aspect was flexibility (anytime/anywhere learning) (average score 2.66) with $98 \%$ of respondents reporting that this was a positive or excellent benefit. This was followed by innovation in the teaching/learning spaces (average score 2.36) and customization of teaching with additional learning options (average score 2.18), both with over $90 \%$ of respondents reporting benefits. Next were the increased autonomy of learners (average score 2.08) and a wide range of software options (average score 2.02) with $75-80 \%$ of respondents reporting benefits. Lastly, engagement with students (average score 1.55 ) was reported, whereby over $50 \%$ reported no benefit but approximately $40 \%$ reported some benefit.

The positive aspect of working online is frequently identified in the literature as benefiting students with flexibility of time and space. Less commonly espoused, though strongly represented here and expanded upon within the qualitative data, is that flexibility is also greatly valued by those teaching online. Precipitated unexpectedly, but embraced by most, was the opportunity to critically reflect on one's own philosophical and pedagogical intent with how things might be done differently and for the better. The need and desire for 


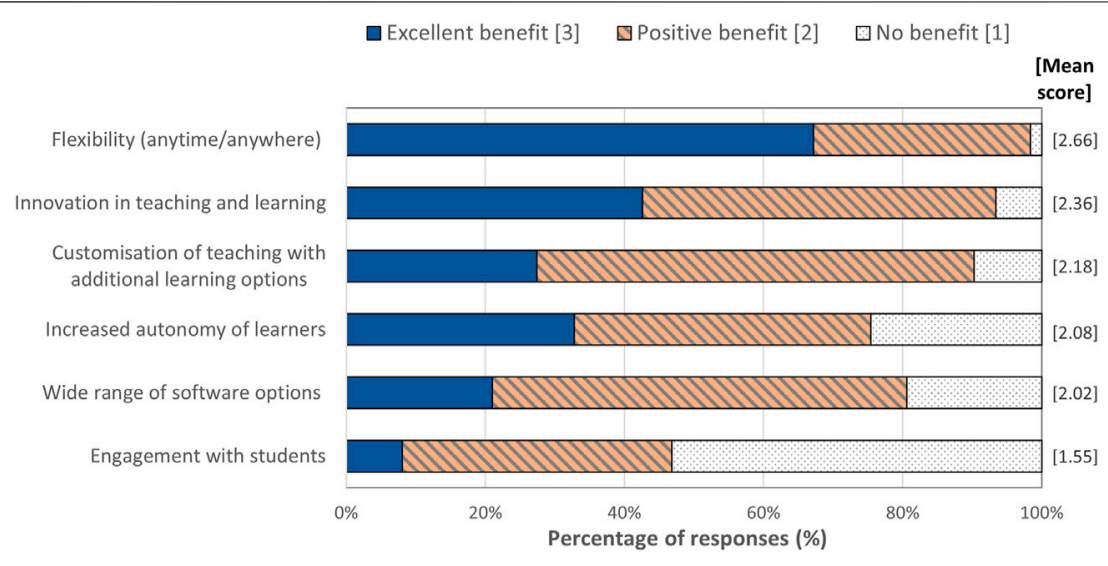

FIGURE 4 | Positive aspects of online/distance learning.

many to be innovative in the creation of new teaching resources was mostly described as a positive outcome.

\subsection{Moving Forward}

During lockdown periods, teaching and learning occurred exclusively online in an emergency mode. Given a lack of certainty as to what the future will hold, future directions remain of interest. Respondents were asked what they believed to be the ideal teaching/learning modes moving forward (Table 3). Blended learning (in the form of flipped classrooms) were preferred by $83 \%$ of respondents as the ideal path in the future. Twenty-four percent expressed an interest in virtual immersive learning (e.g. avatar, simulation, and virtual laboratories). Eighteen percent believed that a return to face-to-face delivery was the best option. Our moving forward is to an uncertain future with regards to delivery modes.

In the open-ended responses, there was strong support for modes of learning and teaching that would allow for continuing flexibility. There was an appreciation of wanting to become more capable and confident in working remotely. Valued was the ability to be creative and to make use of the online space in ways that were complementary rather than replicating what had previously been done. In contemplating what might be enhanced further, there was growing awareness that a blended learning model would likely alter what was done inside of face-to-face learning and online teaching. A change in the dynamics of the learning-teaching relationship was generally seen as increasing autonomy and support for students becoming more self- regulatory and self-evaluative regarding their learning. As much as students are situated as learners, in this instance, academic staff position themselves as learners also. Taking this further, the university was required to learn of, and be responsive to, staff needs.

\section{DISCUSSION}

This research has offered a clearer understanding of the effects of the COVID-19 pandemic and subsequent lockdowns, on teaching practices in a health and science faculty at a university in Auckland, New Zealand. The results have highlighted several challenges and some potential solutions to ease the transition from face-to-face to online or blended modes of delivery in tertiary academic settings.

\subsection{Communication is Key in Emergent Situations}

The pandemic emerged quickly leaving academics feeling stressed, unsure, and unprepared for what was ahead (Rodrigues et al., 2020). There were instances where staff were directed by the university to take an approach which was contradicted shortly thereafter. Many academics found themselves navigating "shifting sands" in both teaching responsibilities and personal lives. Societal norms were in flux

TABLE 3 | Preferred modes of teaching/learning moving forward.

Ideal mode(s) of teaching/learning moving forward $(n=62)$

Face-to-face delivery

Asynchronous online delivery

Flipped classrooms with both online and face-to-face delivery

Online live laboratory interaction and simulations

Virtual immersive learning (e.g. avatar, simulation, virtual laboratory work)

Artificial Intelligence driven learning

Other

\begin{tabular}{cc} 
No & $\%$ \\
\hline 11 & 17.5 \\
4 & 6.4 \\
52 & 82.5 \\
9 & 14.3 \\
15 & 23.8 \\
4 & 6.4 \\
4 & 6.4
\end{tabular}


with personal and professional lives thrown into a state of imbalance (Dwivedi et al., 2020). In the current study one of the complexities affecting the academics at the university was a need for clear and non-conflictual communication. This was evident in statements such as the following:

"Don't frustrate staff with unclear or contradictory communication. Actively and honestly consult with staff as stakeholders for the best methods for moving forward."

As in other parts of the world, the academic staff at the University were forced to adopt new ways of remote working at short notice. Frustration was experienced with several respondents commenting on communications they experienced. Further lack of clarity was witnessed in the communications of the university with students through varied media (e.g. university learning management system, social media, University Facebook page, and the press). Staff wanted to be actively involved with decisions that would affect them in their working relationships with students.

\subsection{IT Resources and Support When Transitioning to Emergency Remote Teaching}

\subsubsection{Equity and Engagement With Technology}

In this study, the highest average concern for academics when pivoting to ERT was concern for students having access to technology. A study of New Zealand teachers demonstrated similar concern particularly for students in remote, rural and lower socio-economic areas (Flack et al., 2020). A survey performed by AUT uncovered a digital divide, whereby six percent of students did not have access to a computer or tablet at home, and $17 \%$ of students did not have broadband (AUT, 2020). The survey was processed through an online system and therefore may well have under-represented student needs. While the university provided laptops and data access packages for staff and students on request, this offer occurred through online platforms. The concern staff felt is best encapsulated in one respondent's statement:

"Do not assume everyone has access to data or Internet connection...I don't and I'm a staff member!"

A statement such as this challenges assumptions made. The expectation that students or staff would openly disclose a need for assistance, let alone respond to online offers of assistance when they may have had limited access, demonstrates a flawed approach. Clearly the mode of communication needs to be broadened and offers of assistance more freely extended. It remains unknown if the above respondent did or did not request a data package during times when the campus was closed.

However, such challenges are not limited to hardware and Internet accessibility, as students and staff also needed to navigate the technology in meaningful ways. As expressed in the following statement, knowledge of what was available was one issue, how to make the best of it another:

"I wanted to really challenge the students with different formats of information delivery and interaction mediums however [I] had very little understanding of what was out there in this space."

"Being forced to push myself to learn new tools and get as close as possible to reproduce what I do in class. Now I am thinking about how to not just try to reproduce but use both face-to-face and online in a complementary way. This enabled me to critically reflect on my teaching, including the sequence of activities used and what each teaching approach/tools enable doing."

For others the ability to engage differently seemed to come with some surprise at how engaging online learning could be.

"I enjoy the flexibility of online learning and the flip classroom approach that places more onus on students to engage. I also enjoyed how some students really ran with the chat bar and other ways to use the features of the platform to communicate."

\subsubsection{Challenges and Benefits of Working From Home}

The idea of work/life balance is nothing new, but the pandemic accelerated imbalance in this area due to 'shifting sands' created by multiple unknowns. There is evidence suggesting that homebased telecommuting negatively affected work-life balance due to increasing work-to-life and life-to-work conflicts (Palumbo, 2020). Part of the reason for this is that working from home has the side effect of diminishing the ability of remote workers to handle the interplay between work-related commitments and daily life activities. This may increase work-to-life conflicts in the form of encroachment of work-related issues in everyday life (Sarbu, 2018). The resultant blurring of boundaries may also increase work-family conflict. However, some benefited from working at home, as the following response indicates:

\section{"I have appreciated that one can derive the satisfaction of delivering good teaching alongside spending time with the family."}

Survey respondents on average reported that not traveling to work was a significant benefit of working from home with $94 \%$ citing this issue a slight or major benefit. Literature supports the idea that measures of stress (e.g. heart rate, blood pressure, skin conductance) are correlated with driving a car to work in some individuals (Paschalidis et al., 2019). By keeping people at home during the pandemic, academic staff may have experienced reduced stress by not travelling to work, as well as more time to complete work-related tasks.

When asked about working from home, the highest average score reported as challenging was too much screen time. Research confirms that visual fatigue and discomfort are induced by viewing screens (Kim et al., 2017). Screen time has increased 
due to a multitude of factors including the need to create more resources, increased student communications, and increased team meetings. While screen time proved to be exhausting for many, this directly influenced the second highest average score of managing work hours. Eighty-six percent of respondents found this issue a slight or major challenge. Managing work hours is a smaller part of a bigger picture involving work-life balance, increased screen time, and increased student expectations. Working remotely in an emergency mode involved both benefits and advantages, which sometimes occurred concurrently.

\subsubsection{Unexpected Benefits of Emergency Remote Teaching: Pedagogical Pivot Necessitated by Pandemic}

When the level four lockdown was initiated in New Zealand, all universities were forced into emergency remote teaching and learning. While there were many challenges with the speed of the lockdown, there were also unexpected benefits discovered by academics working remotely. One such benefit supported in the literature (Roblyer et al., 2009) was increased focus and delivery of what was essential. Many staff reported enjoying the opportunity to revamp their courses to focus on crucial content:

"[Working remotely] has forced me to focus on what really matters and I think my content is much better for it, there was lots of necessary stuff in my previous lectures [I was] forced to do careful planning and the material is much better for it."

Flexibility was another reported benefit of working remotely. While the pandemic forced emergency remote teaching and learning, many students choose to study remotely specifically for the flexibility, hoping they can combine their studies with multiple other responsibilities in their lives (Stone et al., 2019; Dhawan, 2020). This flexibility was described as benefiting students and academics alike:

"Offering more flexibility for students juggling multiple commitments such as child-care and work."

"[A] way for students to engage equitably-students have more time to consider content (can set their own schedule) and have multiple opportunities to review material \& engage (especially asynchronously)."

"[I] appreciated that students could learn from home, and I could work from home at a time when many were losing their jobs."

A further unexpected positive aspect of remote learning is the increased autonomy. Motivation (Latin "to move") provides the fuel for action and increases learner autonomy (Ryznar and Dutton, 2020). Motivation is moldable and can be enhanced by design elements such as generating student belief in the value of course tasks, and then encouraging them positively as to their ability to succeed (Daniel, 2020; Ryznar and Dutton, 2020).
Increased engagement demonstrates improved motivation as noted by one academic:

"I enjoy the flexibility of online learning and the flip classroom approach that places more onus on students to engage. I also enjoyed how some students really ran with the chat bar and other ways to use the features of the platform to communicate."

Increased scope for creativity was also noted as a benefit in remote learning. Research tells us that the key to elevating the reputation of online courses is in giving the power of creativity back to the teacher (Wieland and Kollias, 2020). This process of what is done in the teaching environment was described as concurrently the same and different; that there was increased awareness of how one's academic role was being shaped as much as staff felt they were shaping their own work practices:

"Collaborate Ultra allowed me to draw, write, upload slides... I felt I was teaching using a blackboard in the classroom... not really but similar to that."

"I think there is room for further creativity when working online (loss of sage on the stage and more integrativel immersive learning)."

While for some there is a sense that teaching remotely was forced, there is also an appreciation for the pedagogical pivot as a "next step":

"[ERT] forced me to focus on what really matters and I think my content is much better for it, there was lots of necessary stuff in my previous lectures, forced to do careful planning and the material is much better for it."

\subsection{Moving Forward}

\subsubsection{Developing Expertise as a Teacher in Online Spaces}

With the need to develop capacity as an academic within online spaces, came increased awareness of the need to increase competency and confidence in one's work. Once access to the Internet and appropriate hardware are secured, the shift in focus becomes one of ensuring capacity and confidence (Roddy et al., 2017). A pedagogical shift prompted by the abrupt need to work online is evidenced by the desire to make more student-centric learning spaces:

"The ability to create spaces online where students can access material and our support more easily has been an interesting experience..."

Noteworthy, were differing appreciations for how working online might influence or necessitate new ways of working. These are encapsulated within the commentary of responses ranging from doing what one had done previously but capturing this as a film, through to the development of ways of working that were enhanced by the online media. Evident is a thoughtfulness for moving forward in such unknown space, 
"Lectures were recorded and uploaded on Blackboard for students to look at them at their own time and space."

"The ability to create spaces online where students can access material and our support more easily has been an interesting experience, though also increased workload as a result."

“... however, working on new platforms (BBC, Panopto) took more time to prepare ...."

"Being forced to push myself to learn new tools and get as close as possible to reproduce what I do in class. Now I am thinking about how to not just try to reproduce but use both face-to-face and online in a complementary way. This enabled me to critically reflect on my teaching, including the sequence of activities used and what each teaching approach/tools enable doing."

During lockdown the focus appeared to be on managing the moment regarding supporting students as best as one was able. Supporting staff wanting to embed changes or expand skills moving forward becomes a concern for what Senge (2004) has termed the learning organization. Such organizations provide for enhancement of collective actions, recognizing that actions by individuals tend not to be sustained. Enduring changes are unlikely in the long term without systemic strategic support. Focused attention on the needs of the university, oriented toward facilitative ways of working as a learning organization, is key for future development.

\subsubsection{Sustainability}

The pandemic has highlighted that change and challenge are unavoidable concerns of modern life. Responsiveness to this unexpected event has provided an occasion for taking a more proactive approach. Since the lockdown period, many academic staff and students have chosen or are expecting remote teaching and learning to continue. An opportunity to consider sustainable changes proven effective in enhancing student learning and support is key in moving forward to a new normal.

In the context of the pandemic, some academics did not adapt their pedagogical practice to suit the online learning environment. Practices were limited to uploading existing teaching resources into the online learning management system. However, in-class assessments and examinations were required to be reconfigured for the online environment. Many staff recognized this minimal approach was a less than optimal response. Due to the ERT context, there was not time to consider how students interpreted tasks, took cues from peers, monitored progress, or adapted their approaches. The assumption was made that students had self-regulated in their learning.

Self-regulated learning involves developing an understanding of the task; setting goals and planning; applying study tactics and strategies; and adapting study for the future (Boud et al., 2018). The university did not have time to evaluate whether these abilities were intact for students (and encouraged by academic staff) when the shift to emergency remote learning occurred. Additionally, academics may not have recognized such capabilities as important. Some academics stated they required further help in how to best support students:
"More guidance on effective use of remote teaching and learning that meets educational philosophies and pedagogical theories."
"[The university] needs to consider the quality of teaching and learning resources required for students in the future. This will require investment in the Instructional Design Team/IT infrastructure (i.e. LMS that is 'fit-for-purpose) to support lecturers in the development of a quality teaching and learning experience."
"[Being online] can only succeed if it is well resourced and driven by learning and teaching goals. If it is principally done to save $\$ \$$ it will fail to deliver, and we will lose students."
"More immersive and asynchronous learning (but not just recording of lectures. ..). We need to learn to do this better."

Supporting students in the development of evaluative judgment is integrally entwined with student ability to selfregulate (Boud et al., 2018). Furthermore, evaluative judgment develops over time with students initiating and engaging with a number of significant self-regulatory learning strategies (e.g. strong internal feedback mechanisms). Students capable of evaluative judgment have high motivational regulation, high adoption of self-regulated learning, and better outcomes in academic performance. It is therefore timely for academics to explore ways of developing students' evaluative judgement, especially in remote teaching and learning environments. Challenges such as the shape of assessments, given examinations could not occur on campus, precipitated such discussions. The desire for further professional development was evident within the respondent's comments on the openended questions.

\subsubsection{Flipped Classrooms Preferred Platform Into Future}

While many respondents opted for a flipped classroom, there was no evidence of a cohesive understanding of what this might involve in the open-ended responses. The flipped classroom is a more recent pedagogical method, which employs asynchronous video lectures and practice problems as homework, and active, group-based problem solving in the classroom (Bishop and Verleger, 2013). As a sub-type of blended learning, flipped classrooms are emerging as a promising student-centred paradigm (Kemp and Grieve, 2014). It may therefore be more accurate to suggest that the majority of respondents supported a blended approach moving forward.

Blended learning is a broader category which combines traditional face-to-face learning and e-learning (Bernard et al., 2014). Consideration should be given to what motivates learners and how to best support student needs and demands. Blended learning adds a flexibility dimension to the traditional face-to- 
face learning process along with improved academic achievement.

\subsubsection{Avatar, Simulation, and Virtual Laboratories}

Twenty-four percent of survey respondents expressed an interest in virtual immersive learning (e.g. avatar, simulation, and virtual laboratories) for the future. There are several applications for these learning platforms which have been useful both during the pandemic and beyond (Richey, 2020). Avatar-based learning has been shown to be effective in online teaching (Mkrttchian et al., 2020). Additionally, the use of three-dimensional multi-user virtual environments to provide learners with realistic scenarios in which verbal and non-verbal interactions are simulated has also shown promise in the online learning space (Tseng et al., 2013). The university has been interrupted in its development of these platforms in the climate of the pandemic. Presently, there is a heightened need for professional development of staff relating to course design and pedagogical underpinnings which will enhance all learning and teaching before investing in virtualization planned for laboratory and clinical skill development.

\subsubsection{Institutional Leadership and Strategic Plan for Future}

The challenges of what might be done and strategies for moving forward have never been more urgent for the university as a learning organization.

At the time of the pandemic many academics had never taught remotely. Many were working from what had always been comfortable. Others had embraced learning opportunities applicable to online spaces and were willing to share their expertise. The current experience was hugely reactive. In view of sustainability, the learning organization needs to examine what is needed in supporting staff who want to work more effectively in remote and online spaces. This would involve:

- Clarity as to purpose. Consideration of the philosophical and pedagogical possibilities in teaching and learning within online and remote settings.

- A need to review sustainability within our educational endeavors. This extends beyond a responsiveness of sustaining learning and teaching within online and remote spaces. Strategies for nurturing, developing and imbedding changes recognized by staff as enhancing the educational goals of their work needs to occur.

\section{STRENGTHS AND LIMITATIONS}

Strengths and limitations of this research must be acknowledged. The anonymous and online nature of the survey may have encouraged more honest responses. Respondents may be more likely to share personal information pertaining to sensitive opinions online (Gnambs and Kaspar, 2015) and anonymously (Fear et al., 2012; Merry, 2013). Ultimately using an anonymous online survey to collect data may have minimized the potential presence of social desirability bias (Joinson, 1999), such as respondents downplaying their negative experiences or refusing to share personal struggles that they may perceive as embarrassing. Additionally, the qualitative open-ended questions contributed more in-depth and rich data to the numerical data. Two coders independently coded the qualitative data and another two reviewed the codes. This added to the trustworthiness of the analysis by minimizing the possibility of misinterpretation.

A main limitation was the small sample size, which may have been caused by the restrictions imposed on the recruitment of respondents, with invitations to participate being predominantly restricted to on-campus signage. Ethical requirements limited recruitment to posters on campus and word of mouth in a time when many academic staff continued to work remotely. This influenced the sample size thus limiting the generalizability of the findings but does not detract from the valuable shared experiences.

\section{FUTURE RESEARCH DIRECTIONS}

Future research should include multiple universities with a goal of recruiting a larger sample size. Consideration around how familiar lecturers are with new technologies and different types of online and remote teaching, while realizing different levels of engagement, could provide rich areas of future investigation. It would also be appropriate to explore the differences between how courses are delivered before and after the pandemic along with the permanence of changes. Investigations into student experiences would also be of value knowing what learning and teaching strategies might be most positively received moving forward.

\section{CONCLUSION}

This study has highlighted the experiences and effects of the COVID19 pandemic on educators pivoting to a remote teaching environment at a university in New Zealand. Many academics found themselves navigating "shifting sands" in both teaching responsibilities and personal lives. These challenges included conflicting communication from the university, non-standard access to IT resources, a lack of dedicated space to work from home, and excessive screen-time, all of which contributed to disruptions in work-life balance. More positively, the pivot to remote teaching enabled and encouraged flexibility and creativity, and an opportunity to reflect on what academics do and how this might be best achieved.

This research has brought to the fore a need to consider strategies to sustain learning and teaching even during challenging times. Reiterating the words of one of the respondents, "We need to learn to do this better." This research has provided an opportunity to consider staff responses and responsiveness during challenging times. Noted is an interruption to the assumed roles of learners and educators, with educators also embracing new learning opportunities. The university as a learning organization needs to consider sustainability by nurturing future possibilities in online and remote teaching and learning contexts. 


\section{DATA AVAILABILITY STATEMENT}

The original contributions presented in the study are included in the article/Supplementary Material, further inquiries can be directed to the corresponding author.

\section{ETHICS STATEMENT}

This study was approved by the AUT Ethics Committee (Reference 20/266) and all respondents consented to participate.

\section{AUTHOR CONTRIBUTIONS}

As principal investigator, GE conceived the study, secured funding, progressed the ethics application through to approval, facilitated the research team meetings, and was corresponding author. GE, NiG, NoG, KL, KH, and $\mathrm{AH}$ contributed to the study design. $\mathrm{KL}$ and $\mathrm{NiG}$ analyzed the quantitative data. GE, AH, SA, and NoG analyzed the

\section{REFERENCES}

Almost, J. (2020). The Impact of Covid-19 within Academic Settings: A High-Speed Pivot. Nurs. Leadersh. (Tor. Ont.) 33 (3), 15-19. doi:10.12927/cjnl.2020.26323

Anderson, V. (2020). A Digital Pedagogy Pivot: Re-thinking Higher Education Practice from an HRD Perspective. Hum. Resource Development Int. 23 (4), 452-467. doi:10.1080/13678868.2020.1778999

Aristovnik, A., Keržič, D., Ravšelj, D., Tomaževič, N., and Umek, L. (2020). Impacts of the COVID-19 Pandemic on Life of Higher Education Students: A Global Perspective. Sustainability 12 (8438), 8438. doi:10.3390/su12208438

AUT (2020). AUT Provides Digital Access to Thousands. Retrieved from: https:// news.aut.ac.nz/news/aut-provides-digital-access-to-thousands (Accessed September 21, 2020).

Bearman, M., Dawson, P., Ajjawi, R., Tai, J., and Boud, D. (2020). Re-imagining university Assessment in a Digital World. Cham Switzerland: Springer.

Bernard, R. M., Borokhovski, E., Schmid, R. F., Tamim, R. M., and Abrami, P. C. (2014). A Meta-Analysis of Blended Learning and Technology Use in Higher Education: From the General to the Applied. J. Comput. High Educ. 26, 87-122. doi:10.1007/s12528-013-9077-3

Bewley, D. (1996). Distance Education in New Zealand: An Historical Sketch. J. Distance Learn. 2 (1).

Bhatt, I., and MacKenzie, A. (2019). Just Google it! Digital Literacy and the Epistemology of Ignorance. Teach. Higher Education 24 (3), 302-317. doi:10.1080/13562517.2018.1547276

Bishop, J. L., and Verleger, M. A. (2013). The Flipped Classroom: A Survey of the Research 120th ASEE Annual Conference and Exposition, Atlanta, Georgia. Available at: https://www.asee.org/search/proceedings (Accessed September 24, 2020).

Boud, D., Ajjawi, R., Dawson, P., and Tai, J. (2018). Developing Evaluative Judgement in Higher Education: Assessment for Knowing and Producing Quality Work. Milton Keynes, UK: Taylor \& Francis Group.

Braun, V., and Clarke, V. (2006). Using Thematic Analysis in Psychology. Qual. Res. Psychol. 3 (2), 77-101. doi:10.1191/1478088706qp063oa

Cameron-Standerford, A., Menard, K., Edge, C., Bergh, B., Shayter, A., Smith, K., et al. (2020). The Phenomenon of Moving to Online/distance Delivery as a Result of COVID-19: Exploring Initial Perceptions of Higher Education Faculty at a Rural Midwestern university. Front. Educ. 5 (203). doi:10.3389/ feduc.2020.583881

Conole, G. (2021). Learning Design in Practice: Fostering Different Pedagogical Approaches. Milton Keynes, UK: Taylor \& Francis. qualitative data. All authors helped with interpreting the data, wrote and edited the manuscript. All authors also approved the final manuscript.

\section{FUNDING}

The research assistants on this project (NoG and SA) were supported by a Publication Based Research Fund grant (PBRF) from Auckland University of Technology.

\section{ACKNOWLEDGMENTS}

The authors wish to acknowledge the academic staff in the Faculty of Health and Environmental Sciences at Auckland University of Technology for their participation in this research and their keen ability to share sincere and courageous thinking as we have moved through the 2020 pandemic.

Daniel, S. J. (2020). Education and the COVID-19 Pandemic. Prospects (Paris) 49 (1), 1-6. doi:10.1007/s11125-020-09464-3

Dhawan, S. (2020). Online Learning: A Panacea in the Time of COVID-19 Crisis. J. Educ. Technology Syst. 49 (1), 5-22. doi:10.1177/0047239520934018

Dwivedi, Y. K., Hughes, D. L., Coombs, C., Constantiou, I., Duan, Y., Edwards, J. S., et al. (2020). Impact of COVID-19 Pandemic on Information Management Research and Practice: Transforming Education, Work and Life. Int. J. Inf. Management 55, 102-211. doi:10.1016/j.ijinfomgt.2020.102211

Eagle Hill Consulting (2020). Survey: Pandemic Driving Employee Burnout and Stress. Toledo Business J. 36 (5), 6-7.

EIT InnoEnergy (2020). Teaching Online in Times of Crisis. European Institute of Innovation \& Technology. Available at: https://eit.europa.eu/news-events/news/ eit-innoenergy-teaching-online-times-crisis\&sa $=\mathrm{D} \&$ ust $=160549919044$ 9000\&usg=AOvVaw2XAIXEqGHwOI6vYBWqmc85 (Accessed November 11, 2020).

Favale, T., Soro, F., Trevisan, M., Drago, I., and Mellia, M. (2020). Campus Traffic and E-Learning during COVID-19 Pandemic. Computer Networks 176, 107290. doi:10.1016/j.comnet.2020.107290

Fear, N. T., Seddon, R., Jones, N., Greenberg, N., and Wessely, S. (2012). Does Anonymity Increase the Reporting of Mental Health Symptoms? BMC Public Health 12 (1), 797. doi:10.1186/1471-2458-12-797

Flack, C. B., Walker, L., Bickerstaff, A., Earle, H., and Margetts, C. (2020). Educator Perspectives on the Impact of COVID-19 on Teaching and Learning in Australia and New Zealand. https://www.pivotpl.com/wp-content/uploads/2020/05/ Pivot-Professional-Learning_State-of-Education-Whitepaper_April2020.pdf (Accessed October 17, 2020).

Gamage, K. A. A., Wijesuriya, D. I., Ekanayake, S. Y., Rennie, A. E. W., Lambert, C. G., and Gunawardhana, N. (2020). Online Delivery of Teaching and Laboratory Practices: Continuity of university Programmes during COVID-19 Pandemic. Education Sci. 10 (10), 291. doi:10.3390/educsci10100291

Gnambs, T., and Kaspar, K. (2015). Disclosure of Sensitive Behaviors across SelfAdministered Survey Modes: A Meta-Analysis. Behav. Res. Methods 47 (4), 1237-1259. doi:10.3758/s13428-014-0533-4

Hodges, C., Moore, S., Lockee, B., Trust, T., and Bond, A. (2020). The Difference between Emergency Remote Teaching and Online Learning. https://er.educause. edu/articles/2020/3/the-difference-between-emergency-remote-teaching-andonline-learning (Accessed September 10, 2020).

Houlden, S., and Veletsianos, G. (2020). Coronavirus Pushes Universities to Switch to Online Classes - but Are They Ready? the Conversation. Available at: https:// theconversation.com/coronavirus-pushes-universities-to-switch-to-onlineclasses-but-are-they-ready-132728 (Accessed October 27, 2020). 
Joinson, A. (1999). Social Desirability, Anonymity, and Internet-Based Questionnaires. Behav. Res. Methods Instrum Comput. 31 (3), 433-438. doi:10.3758/BF03200723

Kawaguchi-Suzuki, M., Nagai, N., Akonoghrere, R. O., and Desborough, J. A. (2020). COVID-19 Pandemic Challenges and Lessons Learned by Pharmacy Educators Around the globe. Am. J. Pharm. Educ., 84 (8), ajpe8197-4. doi:10.5688/ajpe8197

Kemp, N., and Grieve, R. (2014). Face-to-face or Face-To-Screen? Undergraduates' Opinions and Test Performance in Classroom vs. Online Learning. Front. Psychol. 5, 1278. doi:10.3389/fpsyg.2014.01278

Kim, D. J., Lim, C. Y., Gu, N., and Park, C. Y. (2017). Visual Fatigue Induced by Viewing a Tablet Computer with a High-Resolution Display. Korean J. Ophthalmol. 31 (5), 388-393. doi:10.3341/kjo.2016.0095

König, J., Jäger-Biela, D. J., and Glutsch, N. (2020). Adapting to Online Teaching during COVID-19 School Closure: Teacher Education and Teacher Competence Effects Among Early Career Teachers in Germany. Eur. J. Teach. Education 43 (4), 608-622. doi:10.1080/02619768.2020.1809650

Mahdy, M. A. A. (2020). The Impact of COVID-19 Pandemic on the Academic Performance of Veterinary Medical Students. Front. Vet. Sci. 7 (594261). doi:10.3389/fvets.2020.594261

Marshall, D. T., Shannon, D. M., and Love, S. M. (2020). How Teachers Experienced the COVID-19 Transition to Remote Instruction. Phi Delta Kappan 102 (3), 46-50. doi:10.1177/0031721720970702

McPhee, I., and Söderström, T. (2012). Distance, Online and Campus Higher Education: Reflections on Learning Outcomes. Campus-Wide Info Syst. 29 (3), 144-155. doi:10.1108/10650741211243166

Merry, S. (2013). Reconceptualising Feedback in Higher Education. New York, N.Y: Routledge.

Mkrttchian, V., Kharicheva, D., Aleshina, E., Panasenko, S., Vertakova, Y., Gamidullaeva, L. A., et al. (2020). Avatar-Based Learning and Teaching as a Concept of New Perspectives in Online Education in Post-Soviet Union Countries. Int. J. Virtual Personal Learn. Environments 10 (2), 66-82. doi:10.4018/IJVPLE.2020070105

New Zealand Ministry of Health (2020). Unite Against COVID-19. New Zealand Government Printer. Retrieved from: https://covid19.govt.nz/alert-system/alertsystem-overview/\#alert-level-4-\%E2\%80\%94-lockdown (Accessed on June 21, 2020).

Nicola, M., Alsafi, Z., Sohrabi, C., Kerwan, A., Al-Jabir, A., Iosifidis, C., et al. (2020). The Socio-Economic Implications of the Coronavirus Pandemic (COVID-19): A Review. Int. J. Surg. 78, 185-193. doi:10.1016/j.ijsu.2020.04.018

Palmer, S. (2012). Understanding the Context of Distance Students: Differences in on- and Off-Campus Engagement with an Online Learning Environment. J. Open, Flexible Distance Learn. 16 (1), 70-82. https://www.jofdl.nz/index.php/ JOFDL/article/view/85/59.

Palumbo, R. (2020). Let Me Go to the Office! an Investigation into the Side Effects of Working from home on Work-Life Balance. Ijpsm 33 (6/7), 771-790. doi:10.1108/IJPSM-06-2020-0150

Paschalidis, E., Choudhury, C. F., and Hess, S. (2019). Combining Driving Simulator and Physiological Sensor Data in a Latent Variable Model to Incorporate the Effect of Stress in Car-Following Behaviour. Analytic Methods Accid. Res. 22, 100089. doi:10.1016/j.amar.2019.02.001

Pather, N., Blyth, P., Chapman, J. A., Dayal, M. R., Flack, N. A. M. S., Fogg, Q. A., et al. (2020). Forced Disruption of Anatomy Education in Australia and New Zealand: An Acute Response to the Covid-19 Pandemic. Anat. Sci. Educ. 13, 284-300. doi:10.1002/ase.1968

Pentaraki, A., and Burkholder, G. J. (2017). Emerging Evidence Regarding the Roles of Emotional, Behavioural, and Cognitive Aspects of Student Engagement in the Online Classroom. Eur. J. Open, Distance E-Learning 20 (1), 1-21. doi:10.1515/eurodl-2017-0001

Ralston, S. J. (2020). Education Has Already Changed: A Brief History of Online Education Platforms. Retrieved April 21 from: https://medium.com/malt-community/ education-has-already-changed-a-brief-history-of-online-learning-platformsfe434042faaa.Malt.com

Rapanta, C., Botturi, L., Goodyear, P., Guàrdia, L., and Koole, M. (2020). Online university Teaching during and after the Covid-19 Crisis: Refocusing Teacher
Presence and Learning Activity. Postdigit. Sci. Educ. 2 (3), 923-945. doi:10.1007/s42438-020-00155-y

Richey, S. L. (2020). SIMULATION TRAINING. COVID-19 Simulation Training: Resources for Healthcare Workers. J. Respir. Care Pract. 33 (6), 20-21.

Roblyer, M. D., Porter, M., Bielefeldt, T., and Donaldson, M. B. (2009). Teaching Online Made Me a Better Teacher: Studying the Impact of Virtual Course Experiences on Teachers' Face-To-Face Practice. J. Comput. Teach. Education 25 (4), 121-126. https://eric.ed.gov/?id=EJ844209.

Roddy, C., Amiet, D. L., Chung, J., Holt, C., Shaw, L., McKenzie, S., et al. (2017). Applying Best Practice Online Learning, Teaching, and Support to Intensive Online Environments: An Integrative Review. Front. Educ. 2 (59). doi:10.3389/ feduc.2017.00059

Rodrigues, M., Franco, M., and Silva, R. (2020). COVID-19 and Disruption in Management and Education Academics: Bibliometric Mapping and Analysis. Sustainability 12 (18), 7362. doi:10.3390/su12187362

Ryznar, M., and Dutton, Y. M. (2020). Lighting a Fire: The Power of Intrinsic Motivation in Online Teaching. Syracuse L. Rev. 70 (1), 73-114.

Sarbu, M. (2018). The Role of Telecommuting for Work-Family Conflict Among German Employees. Res. Transportation Econ. 70 (1), 37-51. doi:10.1016/j.retrec.2018.07.009

Sălceanu, C. (2020). Higher Education Challenges during Covid-19 Pandemic. A Case Study. Revista Universitara de Sociologie 16 (1), 104-114. https://search-ebscohostcom.ezproxy.aut.ac.nz/login.aspx?direct=true\&db=sih\&AN=144573416\&site=edslive.

Seelig, C., Cadwallader, A., and Standring, D. (2019). Transformational Change in Delivery at Open Polytechnic, New Zealand. J. Learn. Development 6 (1), 37-48. https://eric.ed.gov/?id=EJ1212523.

Selwyn, N. (2016). Is Technology Good for Education? Cambridge, England: Polity. Senge, P. M. (2004). Presence: Human Purpose and the Field of the Future. Cambridge, MA: Society for Organizational Learning.

Sokal, L. J., Trudel, L. G. E., and Babb, J. C. (2020). Supporting Teachers in Times of Change: The Job Demands- Resources Model and Teacher Burnout during the COVID-19 Pandemic. Ijce 3 (2), 67-74. doi:10.11114/ijce.v3i2.4931

Thomas, J., and Harden, A. (2008). Methods for the Thematic Synthesis of Qualitative Research in Systematic Reviews. BMC Med. Res. Methodol. 8 (45). doi:10.1186/1471-2288-8-45

Tseng, J.-J., Tsai, Y.-H., and Chao, R.-C. (2013). Enhancing L2 Interaction in Avatar-Based Virtual Worlds: Student Teachers' Perceptions. Australas. Soc. Comput. Learn. Tertiary Education 29 (3), 357-371. doi:10.14742/ajet.283

UNESCO Institute for Statistics data (2020). COVID-19 Impact on Education. UNESCO. Retrieved from https://en.unesco.org/covid19/educationresponse.

White, M. (1982). Distance Education in Australian Higher Education - a History. Distance Education, 3, 255-278. doi:10.1080/0158791820030207

Whittle, C., Tiwari, S., Yan, S., and Williams, J. (2020). Emergency Remote Teaching Environment: a Conceptual Framework for Responsive Online Teaching in Crises. Ils 121 (5/6), 311-319. doi:10.1108/ILS-04-2020-0099

Wieland, N., and Kollias, L. (2020). E-Learning during Covid-19. Vet. Rec. 186 (2), 521-592. doi:10.3991/ijac.v13i2.16779

Conflict of Interest: The authors declare that the research was conducted in the absence of any commercial or financial relationships that could be construed as a potential conflict of interest.

Publisher's Note: All claims expressed in this article are solely those of the authors and do not necessarily represent those of their affiliated organizations, or those of the publisher, the editors and the reviewers. Any product that may be evaluated in this article, or claim that may be made by its manufacturer, is not guaranteed or endorsed by the publisher.

Copyright $\odot 2021$ Erlam, Garrett, Gasteiger, Lau, Hoare, Agarwal and Haxell. This is an open-access article distributed under the terms of the Creative Commons Attribution License (CC BY). The use, distribution or reproduction in other forums is permitted, provided the original author(s) and the copyright owner(s) are credited and that the original publication in this journal is cited, in accordance with accepted academic practice. No use, distribution or reproduction is permitted which does not comply with these terms. 